
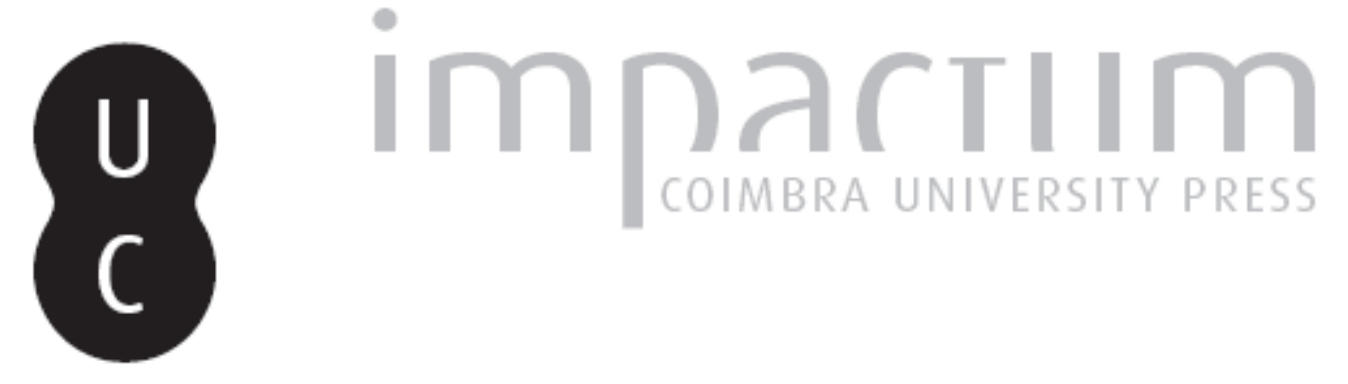

\title{
Filosofia como iniciação e a técnica do Logos no Fédon
}

Autor(es): $\quad$ Souza, Eliane de

Publicado por: Annablume Clássica; Imprensa da Universidade de Coimbra

URL persistente:

URI:http://hdl.handle.net/10316.2/38300

DOI:

DOI:http://dx.doi.org/10.14195/1984-249X_16_6

Accessed : $\quad$ 26-Apr-2023 12:54:42

A navegação consulta e descarregamento dos títulos inseridos nas Bibliotecas Digitais UC Digitalis, UC Pombalina e UC Impactum, pressupõem a aceitação plena e sem reservas dos Termos e Condições de Uso destas Bibliotecas Digitais, disponíveis em https://digitalis.uc.pt/pt-pt/termos.

Conforme exposto nos referidos Termos e Condições de Uso, o descarregamento de títulos de acesso restrito requer uma licença válida de autorização devendo o utilizador aceder ao(s) documento(s) a partir de um endereço de IP da instituição detentora da supramencionada licença.

Ao utilizador é apenas permitido o descarregamento para uso pessoal, pelo que o emprego do(s) título(s) descarregado(s) para outro fim, designadamente comercial, carece de autorização do respetivo autor ou editor da obra.

Na medida em que todas as obras da UC Digitalis se encontram protegidas pelo Código do Direito de Autor e Direitos Conexos e demais legislação aplicável, toda a cópia, parcial ou total, deste documento, nos casos em que é legalmente admitida, deverá conter ou fazer-se acompanhar por este aviso.

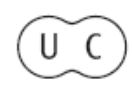


16

jan/apr

2016

issn 2179-4960

e-issn 1984-249X

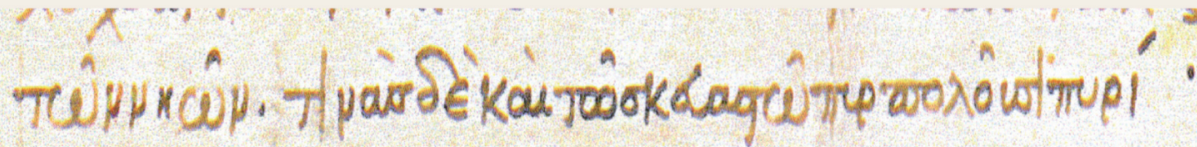

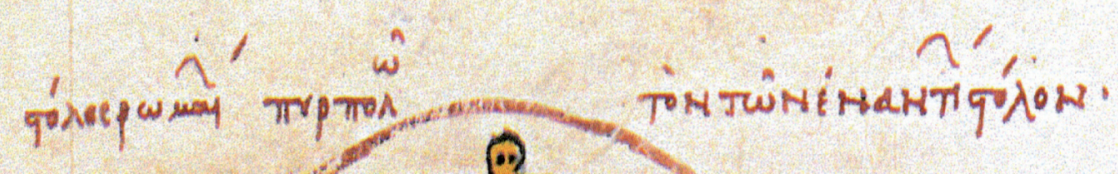
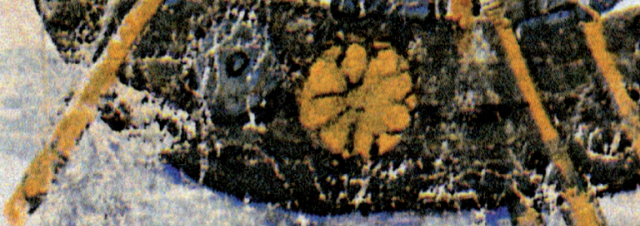

,

.
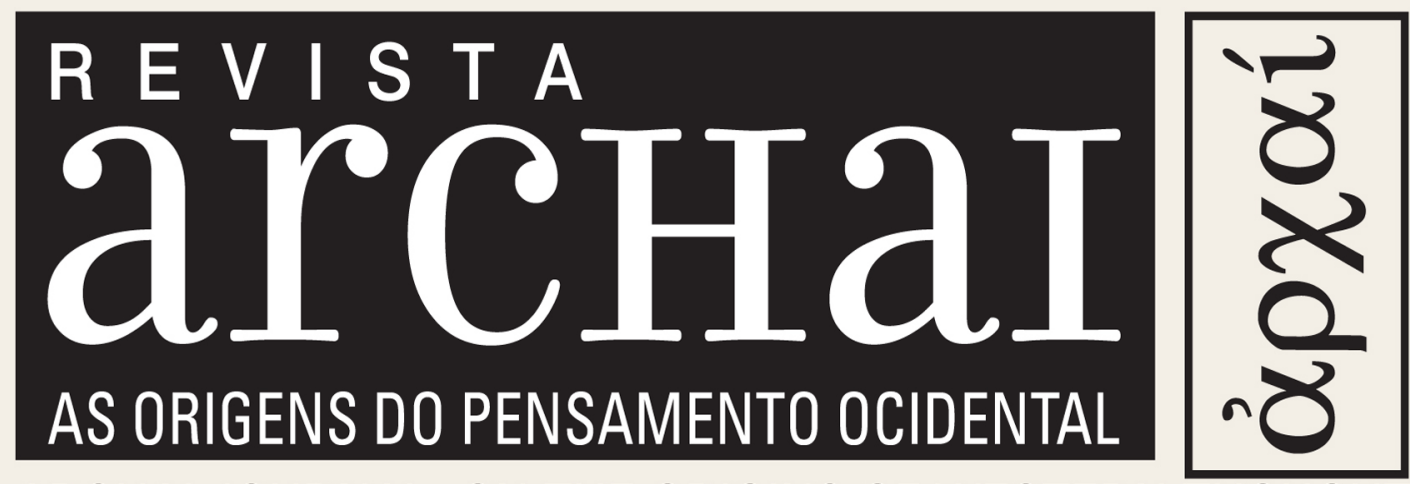

ARCHAI JOURNAL: ON THE ORIGINS OF WESTERN THOUGHT

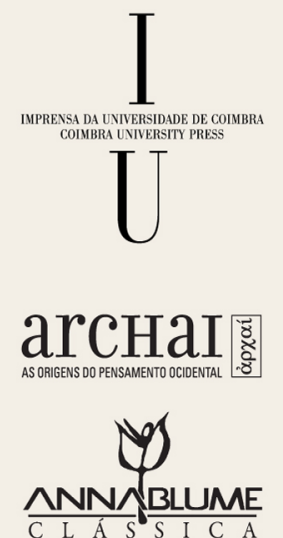




\section{FILOSOFIA COMO INICIAÇÃO E A TÉCNICA DO LOGOS NO FÉDON}

\section{Philosophy as initiation and The TeChNique of logos in The PhaEdo}

SOUZA, E. de (2016). Filosofia como iniciação e a técnica do logos no Fédon. Archai, n. 16, jan.-apr., p. 115-125

DOI: http://dx.doi.org/10.14195/1984-249X_16_6

Resumo: O conhecimento, caracterizado na seção inicial do Fédon como posse das formas pela alma, é alcançável em condições especiais: a alma pura só pode encontrar os seres puros após a morte e, para que isso ocorra, é preciso que o verdadeiro filósofo se dedique à filosofia como uma iniciação. Porém, na seção final do diálogo, o trabalho com os logoi e com as hipóteses parece constituir uma forma mais dinâmica de filosofia. Pretendo examinar a relação entre a parte inicial do diálogo, na qual o conhecimento obtido pela alma em condições plenamente favoráveis está associado aos mistérios, e a seção final, que apresenta a técnica do discurso como uma possibilidade de conhecimento para o homem em sua condição de mistura corpo e alma.

Palavras-chave: Filosofia, conhecimento, discurso.

\section{$\operatorname{arcHaI}$}

n. 16, jan.-apr. 2016 


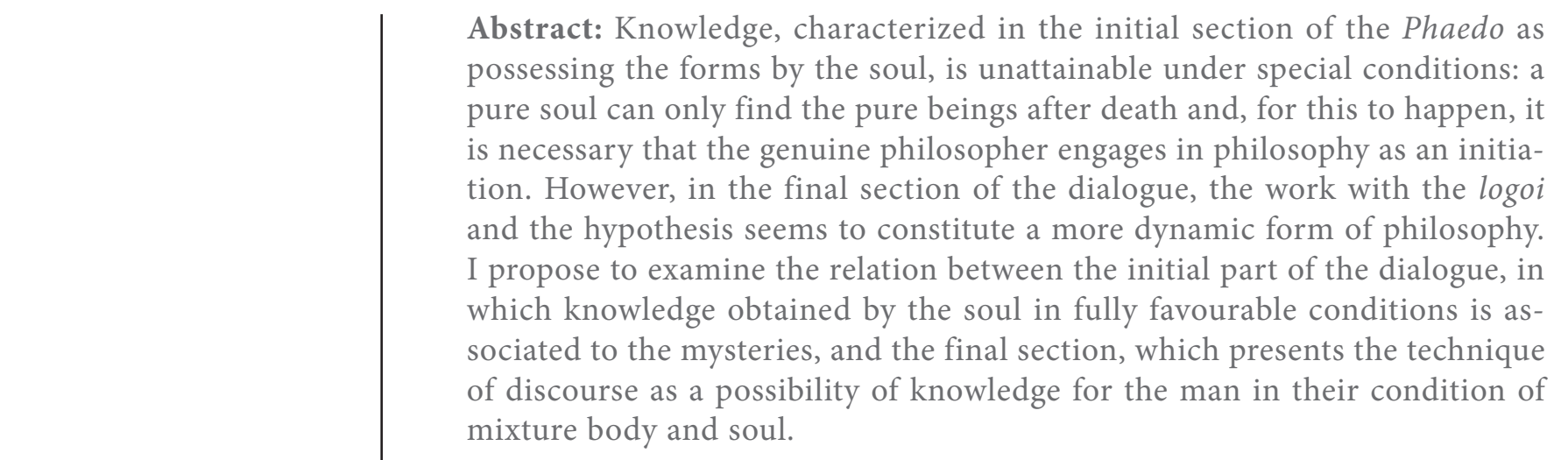

archaI

AS ORIGENS DO PENSAMENTO OCIDENTAL

n. 16, jan.-apr. 2016

SOUZA, E. de,

Filosofia como iniciação

e a técnica do logos no

Fédon p. 115-125

Keywords: Philosophy, knowledge, discourse. 
Com base em estudos influentes como os de Adlury (2006) e Riedweg (1987), é possível afirmar-se que o uso da linguagem dos mistérios em Platão tem forte significado filosófico. A estreita conexão entre o texto platônico e os mistérios de Deméter e Perséfone levaram Adlury (2006, p. 413) a considerar que a filosofia socrática e os rituais iniciáticos não são atividades separadas ${ }^{1}$. A presente análise, no entanto, não propõe um aprofundamento do sentido religioso da filosofia platônica, na medida em que pretende sobretudo explorar a noção de conhecimento exposta no Fédon.

O conhecimento, caracterizado na seção inicial do diálogo como posse das formas pela alma, só pode ser alcançado em condições muito especiais, ligadas aos mistérios. A alma encontrará os seres apenas após a morte e, para que isso ocorra, é preciso que o filósofo se dedique à filosofia como uma iniciação. Porém, na seção final do diálogo, o trabalho com os logoi aparece como uma possibilidade para o conhecimento, digamos, em vida. Proporei que, no Fédon, o conhecimento ocorre nesses dois modos distintos, porém relacionados: aquele que vou chamar de "conhecimento pleno", obtido pela alma em condições completamente favoráveis, e o "conhecimento possível", sujeito à precariedade epistêmica em que se encontra a alma quando ligada ao corpo ${ }^{2}$. Pretendo trabalhar a relação entre a parte inicial do diálogo (60b-69e), na qual o conhecimento pleno está associado aos mistérios e a uma concepção da filosofia como iniciação, e a seção 99e-102a, que representa a técnica do discurso anunciada no intermédio em 88c-91e.

$\mathrm{Na}$ seção inicial do Fédon, temos, associada à fala da personagem Sócrates, uma distinção entre o comum das pessoas - aqueles que perseguem o prazer - e o verdadeiro filósofo. A figura do verdadeiro filósofo é construída sobre a ideia de que a filosofia é uma preparação para a morte. Em Fédon 64a, Sócrates diz que os que se dedicam à filosofia têm como alvo morrer e estar morto. Estar morto é "'nada mais do que a separação da alma e do corpo" e, completa, "a alma, uma vez separada do corpo, subsiste em si e por si mesma (auto kathiauto)" $(64 c)^{3}$. Aquele que relega a satisfação dos prazeres é o verdadeiro filósofo (aletes philosophos), que separa a alma da comunhão (koinonia) com o corpo (64e).

O verdadeiro filósofo vê o corpo como empecilho para a realização do seu desejo de encontrar os seres (ta onta). Estes se tornam manifestos pelo raciocínio (toi logizestai - 65c) e as melhores condições para o raciocínio se dão com a alma isolada dos sentidos e dos prazeres e sofrimentos. Assim, se pode contemplar a verdade:

Ou pelo corpo se chega à contemplação da absoluta verdade delas (to aletestaton teoreitai) [da grandeza, da saúde, da força], ou então o processo é outro, e aquele de nós que mais profundamente se dispuser a meditar na realidade mesma das coisas que observa é quem mais perto está de atingir o conhecimento de cada uma delas.[...] Só poderá realiza-lo em plena pureza (katarotata) o

\section{arcHaI圈}

n. 16, jan.-apr. 2016

SOUZA, E. de, Filosofia como iniciação e a técnica do logos no Fédon p. 115-125 


\section{$\operatorname{arcHaI}$

n. 16, jan.-apr. 2016

SOUZA, E. de, Filosofia como iniciação e a técnica do logos no Fédon p. 115-125 homem que, na medida das suas forças, for ao encontro de cada um dos seres exclusivamente pela via do pensamento (meta tou logismou) (65e).

Segundo esse modelo de filosofia, não há esperança para o conhecimento enquanto a alma estiver associada ao corpo:

A experiência mostra-nos efetivamente que, para conhecermos com clareza um dado objeto, é indispensável que nos libertemos da nossa realidade física e observemos as coisas em si mesmas, pelo simples intermédio da alma. E então sim, ser-nos-á dado, ao que parece, alcançar o alvo das nossas aspirações, essa sabedoria (phronesis) de que nos dizemos amantes - depois de morrermos, já não em vida, como a lógica do argumento pressupõe. Com efeito, se, associados ao corpo, nada podemos conhecer com clareza (meta tou somatos meden kataros gnonai), das duas uma: ou tal aquisição da sabedoria não existe, ou apenas se concretiza após a morte, precisamente quando (e não antes...) a alma existir em si por si, independentemente (choris) do corpo (66d-67a).

Logo em seguida, Sócrates impõe outra condição ao verdadeiro saber: devemos, em vida, nos afastar o máximo possível de estar em companhia (homilomen) ou em comunhão (koเnonomen) com o corpo (67a). O verdadeiro filósofo, que almeja alcançar a phronesis após a morte, quando a alma pura pode encontrar os seres puros, deve estar preparado ainda em vida, purificado no pensamento:

E daí que não encare sem uma alegre esperança esta viagem que agora me é imposta, e, como eu, qualquer outro que sentisse o seu espirito (dianoia) preparado e, por assim dizer, purificado (67c).

A purificação, então, é esclarecida em 67c-d. Segundo um logos antigo, a katharsis corresponde à separação da alma em relação ao corpo "quer na vida presente quer na futura". Podemos pensar na morte real, a destruição do ser vivo, e na morte metafórica, quando a alma se concentra para se isolar do corpo. O exercício de morrer e estar morto ao qual o filósofo se dedica seria uma metáfora desse afastamento. O verdadeiro filósofo deve se purificar do corpo e do sensível e trabalhar com a alma "o mais possível em si e por si mesma" (65c-66a). Por isso, os purificados encaram com alegria "essa partida para o além onde, ao lá chegarem, há a esperança de alcançar aquilo que ardentemente amavam em vida - ou seja, a sabedoria" (68a).

A partir de 69b, é fornecido um sentido ético para a filosofia como iniciação. Temperança, justiça e coragem são meios de purificar a alma dos prazeres, receios, sofrimentos e tudo aquilo que vem do corpo, e a própria phronesis é um tipo de purificação. Sócrates conclui fazendo uma referência aos mistérios:

É provável, pois, que os fundadores dos nossos ritos mistéricos não fossem homens medíocres, antes pelo contrário, desde há muito nos sugerissem a verdade, ao asseverar que todo aquele que chega ao Hades sem ter sido iniciado há de jazer na lama, enquanto aquele que vai purificado e iniciado habitará, 
ao lá chegar, na companhia dos deuses. É que, como dizem os entendidos nos Mistérios, 'muitos são os portadores de tirso, mas poucos os bacantes'; ora, estes últimos, quer-me parecer que não são outros senão os que se consagraram, no verdadeiro sentido da palavra, à filosofia. (69c-d)

Segundo Bernabé (2011, p. 67), Platão faz interpretação alegórica do verso "os que não são iniciados se afogarão na lama do Hades" e seu sentido profundo é de que os iniciados são os verdadeiros filósofos.

Toda a seção até 69d é escrita sob a inspiração do medo da morte e da tentativa de lidar com ele. Até aqui, não temos nenhuma novidade; vários comentadores escreveram muitas páginas sobre isso. $\mathrm{O}$ que me interessa salientar é que a seção inicial do Fédon é feita sob a perspectiva do verdadeiro filósofo, o iniciado que se purifica para que, após a morte, a alma pura encontre os seres puros (e aqui sigo de perto a interpretação de Burger, 1984). No âmbito da verdadeira filosofia, a alma em estado puro conhecerá por si mesma o que é puro e sem mistura. O vocabulário usado para descrever a ação cognitiva do verdadeiro filósofo é a da posse (Burger, 1984, p. 41): ele busca adquirir a verdade e a sabedoria (ktaomai aleteia te kai phronesis). Essa aquisição só será possível se corpo e alma forem separados. Isso é o que eu chamo de conhecimento pleno. $\mathrm{O}$ verdadeiro filósofo vive a preparação para a morte como uma purificação de toda contaminação corpórea, buscando adquirir a phronesis, que só será plenamente encontrada pela alma em estado puro após a morte. O humano, o lugar da mistura corpo e alma, deve morrer para que a phronesis seja adquirida. Não há lugar para o homem no plano do conhecimento.

Ao colocar o contato da alma pura com as formas puras na perspectiva religiosa, Platão mostra que a alma só pode alcançar os seres puros em uma condição muito especial - separada do corpo. O conhecimento pleno, portanto, aparece no início do Fédon na condição de separação completa entre corpo e alma. O recurso aos mistérios seria uma maneira de lidar com o inteligível, indicando, ao mesmo tempo, um modo de vida e um limite para o conhecimento ${ }^{4}$.

Em 85c-d, contudo, a personagem Símias propõe uma opção ao conhecimento sem que se lance mão da presença órfica:

Por mim, Sócrates, acho, como talvez também tu, que um conhecimento exato nesse tipo de matérias ou é impossível ou extremamente difícil de adquirir em vida; mas, por outro lado, não criticar em todos os seus aspectos as afirmações que nesse domínio se produzem, ou renunciar a fazê-lo antes de ter esgotado todas as possibilidades de exame, é bem sinal de fraqueza de espírito... Ora, nesse campo, as perspectivas que temos são estas: aprendermos a verdade de outrem, ou descobri-la nós mesmos, ou ainda, caso qualquer dessas hipóteses seja inviável, escolhermos, dentre as doutrinas humanas, a que nos parecer melhor e menos falível - a menos que se consiga, com maior segurança e ausência de risco, embarcar em transporte mais sólido do que este, quero dizer, uma doutrina revelada.

\section{arcHaI圈}

n. 16, jan.-apr. 2016

SOUZA, E. de, Filosofia como iniciação e a técnica do logos no Fédon p. 115-125 


\section{archaI \\ AS ORIGENS DO PENSAMENTO OCDENTA}

n. 16, jan.-apr. 2016

SOUZA, E. de,

Filosofia como iniciação e a técnica do logos no

Fédon p. 115-125
Como nota Casertano (2014, p. 6), temos a opção entre um logos divino, que diz certezas, e um humano, que, com a consciência de não poder alcançar conhecimentos claros, procura tornar sempre corretas as conclusões a que chega. Assumindo que essa é a perspectiva da personagem Sócrates, e a de Platão, proponho que o que chamei de conhecimento pleno, a posse de conteúdos claros dados à alma de modo completo, encontra uma alternativa no Fédon, um conhecimento possível. Vejamos como ela se mostra no diálogo.

No início do Fédon, corpo e alma têm papéis bem definidos e o logos aparece como expressão da psyche. No intermédio em 88c-91e, Sócrates é acometido por um medo maior do que o medo da própria morte - o medo da morte do logos, caso não consiga sustentar seu argumento sobre a imortalidade da alma contra as objeções de Símias. O medo da morte do logos é comparado à Hidra e, para confrontar o monstro, Sócrates conta com a ajuda de Fédon.

O intermédio marca, no diálogo, uma divisão entre conhecimento pleno e conhecimento possível. A partir daí, Sócrates deixa de falar da alma em estado puro e sua preocupação parece ser em relação ao homem como misto de corpo e alma. A filosofia perde seu caráter de purificação e de morrer e estar morto para tornar-se técnica para manter vivo o logos e se livrar do risco da misologia.

Na sua origem, a misologia é comparada à misantropia. Podemos desenvolver aversão às pessoas e aos logoi por termos passado por sucessivas decepções. A semelhança entre o plano lógico e o plano das relações humanas, porém, está apenas na decepção que se tem com o que se espera, seja dos logoi, seja das pessoas, já que a causa da decepção é diferente. Quando se trata das relações humanas, tem-se decepção ao esperar que as pessoas possuam características extremas que possam ser facilmente distinguidas em um par de opostos, como por exemplo bom e mau. Isso, porém, diz Sócrates, não é o que acontece. As qualidades opostas são raras e as intermediárias são infindáveis nas pessoas e nas coisas (90a). A falta de experiência em lidar com essas qualidades causa decepção. Já entre os logoi, há dois opostos em questão, o verdadeiro e o falso, e não há intermediários entre eles. A decepção se dá quando falta uma técnica para distinguir entre esses opostos:

Na verdade, é noutro aspecto que falo de semelhança [entre misantropia e misologia], quando, por exemplo, uma pessoa sem qualquer experiência de argumentos (logos techne) toma por verdadeiro o primeiro que lhe aparece, para pouco depois o reputar de falso (quantas vezes com razão, mas quantas vezes sem!) e assim sucessivamente com outro e com outro. E tal é, em especial, o caso dos que passam a vida a argumentar pró e contra: bem sabes como por fim se convencem de terem atingido o cume da sabedoria, de serem os únicos a concluir que nada de são (higies) ou de seguro (bebaion) há nas coisas (ton pragmaton) como nos argumentos (ton logon). (90b-c) 
Apesar da origem comum entre misologia e misantropia, a possibilidade de escapar do perigo da misologia requer o reconhecimento de sua diferença com a misantropia, pois o logos não possui a mesma característica da natureza humana de estar em um ponto intermediário entre opostos. No $\log o s$, verdade e falsidade são polos excludentes. Isso permite que se possa argumentar a favor ou contra um tema sem critério. Tal oscilação pode levar à conclusão de que não é possível ter segurança nos logoi que falam sobre os seres. O reconhecimento dos critérios que determinam a solidez do logos exige uma techne para poder reconhecê-los e saber atuar da melhor maneira sobre eles, ou seja, para reconhecer sua verdade ou falsidade. É essa técnica que Sócrates introduzirá na sequência.

Pensando ainda na perspectiva do verdadeiro filósofo, o anseio do conhecimento pleno dos seres o leva a acreditar na clareza e na verdade da sabedoria pura que ele quer possuir, porém a frustração em obter tal conhecimento provoca uma decepção e a consequente conclusão de insuficiência daquilo que é acessível através do logos. O verdadeiro filósofo, em seu desejo de conhecimento pleno, corre o risco de cair em misologia e se auto-impor um obstáculo ao conhecimento. Ele dirige medo tanto ao corpo quanto aos logoi (Burger, 1984, p. 118). Por não admitir os limites do conhecimento, o verdadeiro filósofo crê que os logoi não sao confiáveis. No entanto, Sócrates adverte Fédon da necessidade de tomar cuidado contra essa crença (90e). Apenas com a techne do logos é possível escapar desse perigo, pois, como Sócrates vai divulgar no decurso do diálogo, a prevenção da misologia depende de abandonar o desejo de conhecimento pleno do seres a fim de preservar a confiança na possibilidade do conhecimento possível através dos logoi.

Sócrates indica, neste interlúdio central, a sua distância em relação ao verdadeiro filósofo do proêmio. Assim como a seção inicial do diálogo foi escrita sob a perspectiva do verdadeiro filósofo, que busca a filosofia como iniciação para que, após a morte, sua alma tenha um encontro imediato com os seres puros, do intermédio em diante Sócrates parece se libertar dessa figura construída frente ao medo da morte e se lança na construção de um conhecimento baseado em hipóteses. A partir de 99d, a filosofia assume a característica de investigação filosófica como uma techne do logos.

Ao falar de sua trajetória filosófica, Sócrates diz:

Depois disso, uma vez desiludido da observação dos seres (ta onta skopon), achei por bem acautelar-me, não viesse a acontecer-me a mim o mesmo que àqueles que contemplam e observam o sol em momentos de eclipse: é sabido que alguns chegam a perder a vista, se não for através da água ou de qualquer outro meio que mirem a sua imagem (eikona). E, com pensamentos mais ou menos deste teor (dienoethen), receei ficar irremediavelmente cego de espírito, caso persistisse em fixar os olhos nas coisas (edeisa ta pragmata), em tentar tocar-lhes diretamente (haptesthai) com meus cinco sentidos (99d-e).

\section{arcHaI圈}

n. 16, jan.-apr. 2016

SOUZA, E. de, Filosofia como iniciação e a técnica do logos no Fédon p. 115-125 


\section{$\operatorname{arcHaI}$}

n. 16, jan.-apr. 2016

SOUZA, E. de, Filosofia como iniciação e a técnica do logos no Fédon p. 115-125
A cegueira da alma, aqui, parece ser uma referência à passagem 66d-e, correspondente à tentativa do verdadeiro filósofo de alcançar a phronesis pelo contato direto da alma com ta pragmata:

Para conhecermos com clareza (dedeiktai) um dado objeto, é indispensável que nos libertemos de nossa realidade física (katharos) e observemos as coisas em si mesmas, pelo simples intermédio da alma (aute te psyche theateon auta ta pragmata) (BURGER, 1984, p. 42).

Se essa interpretação estiver correta, temos, na seção final do Fédon, uma crítica ao verdadeiro filósofo que almeja a posse do conhecimento pleno. Ficar cego da alma, na analogia exposta em 99d-e, é não conseguir mais ver o objeto da busca por insistir na tentativa de olhar o que não pode ser visto. Se os seres puros só podem ser alcançados pela alma pura após a morte, tentar alcançá-los em nossa condição de mistura corpo e alma nos fará cegos. O árduo desejo de possuir as coisas em si mesmas por simples intermédio da alma, sem outra possibilidade para o conhecimento humano, seria responsável pelos riscos de misologia ou de cegueira da alma. O trabalho da alma em sua associação com o corpo será com imagens, ou, como Sócrates vai mostrar, com os logoi. Um estudo dos seres por meio de imagens, eu proponho, equivale ao conhecimento possível para o homem sujeito às condições da mistura corpo e alma.

O correto procedimento para o estudo dos logoi é descrito em 100a, em dois passos:

a. partindo em cada caso do pressuposto (hypothémenos) que julgo ser mais seguro (errômenestatos),

b. tudo o que se me afigura em concordância (sumphonein) com ele tomo por verdadeiro (alethe), quer no tocante às causas quer a qualquer outro aspecto; e, caso contrário, não o aceito como tal.

O passo $a$, o pressuposto ou hipótese que se julga mais segura (em $101 \mathrm{~d}$, o hypothemenos assume o caráter de hypothesis), é condição de possibilidade do passo $b$ (Mombello, 2003, p. 1). A expressão 'sumphonein' - 'ser consistente com' ou 'ser implicado por' - assinala que a proposição é uma consequência logicamente necessária da hipótese (Robinson, 1953, p. 126). Daí se conclui que a verdade só é possível se se conta com a hipótese que se julga mais segura (errômenestatos, fortíssima). Sócrates não explica o que é a hipótese fortíssima, mas o texto mostra que deve ser o logos capaz de gerar uma firme convicção e adesão do interlocutor, como vemos nessa passagem:

Vou tentar explicar-te a espécie (to eidos) de causa a que me tenho aplicado (pepragmateumai). Para tanto, há que voltar a essas noções em que já por demais se insistiu: por aí começarei, pois, tomando por pressuposto (hypothemenos) a realidade de um belo, que existe em si e por si mesmo (ti kalon 
auto kath'hauto), de um bem, de um grande e assim por diante (panta). Se neste ponto me dás razão e aceitas a existência de coisas como estas, espero bem, a partir delas, explicar-te qual seja essa causa e descobrir o que faz com que a alma seja imortal.

No exemplo utilizado por Sócrates, se toma como hypothemenos a existência do belo em si por si, do bom, do grande e de todas as demais coisas que indicam o que, em termos atuais, chamaríamos de predicados. Daí se requer o acordo do interlocutor para provar a imortalidade da alma. Um logos assim é capaz de gerar uma firme convicção. A demanda do acordo reforça o caráter hipotético daquilo a que se faz referência (a existência do belo, do bom, do grande...). O acordo de Cebes a essa fala de Sócrates é um exemplo de adesão e convicção que caracteriza o trabalho com a hipótese que se julga mais segura e é tomada como verdadeira.

A técnica do logos, na sequência, examina o modo como se dá o acesso aos seres puros, ainda que no Fédon isso se faça segundo uma ideia "primária e talvez ingênua". Aqui, a participação aparece como a hipótese em questão, aceita por Cebes:

Ora, vê se pensas também como eu quanto ao que daqui se infere. Por mim, parece-me efetivamente que, se alguma coisa bela existe além do belo em si, a única e exclusiva razão de assim ser é o fato de participar (metechei) desse mesmo belo. E falo assim de todos os casos semelhantes. Estas de acordo com uma explicação deste gênero? - Sim, estou - respondeu. - Ora, aí tens - prosseguiu -, por que razão as outras causas, as ditas "cientificas", não as entendo nem reconheço por tal: se alguém hoje me disser que determinado objeto é belo em virtude do seu colorido, pois bem: explicações dessas mando-as passear, só sorvem para me confundir! E detenho-me simplesmente nesta ideia, primaria e talvez ingênua, de que o que faz a beleza de um objeto não é outra coisa senão o belo em si, seja por uma presença, seja por uma participação ou por qualquer outro processo que torne essa relação possível. Não é, alias, nisso que faço propriamente questão, mas sim em que é graças ao belo que todas as coisas belas são belas. Resposta mais segura do que esta, não a encontro, seja para mim mesmo seja para qualquer outro. E estou convicto de que, apoiado nela, piso terreno seguro, sem riscos de jamais cair, quando a mim mesmo ou a qualquer outro respondo que é graças ao belo que as coisas belas são belas... Ou não pensas do mesmo modo? - Sim, penso (100c-e).

A beleza, da qual as coisas belas participam, a grandeza, da qual as coisas grandes participam, ou seja, as formas que estão presentes nos sensíveis e são causas das suas qualidades, aparecem, nessa seção do Fédon, não como um conhecimento pleno, uma visão imediata, um encontro da alma pura com as formas puras. A argumentação de Sócrates mostra que quem é de fato um filósofo (101e) deve seguir o procedimento proposto para observação dos seres (ta onta) - estudar os logoi para reconhecer neles a verdade dos seres:

\section{arcHaI圈}

n. 16, jan.-apr. 2016

SOUZA, E. de, Filosofia como iniciação e a técnica do logos no Fédon p. 115-125 


\section{arcHaI \\ AS ORIGENS DO PENSAMENTO OCIDENAI}

n. 16, jan.-apr. 2016

SOUZA, E. de,

Filosofia como iniciação e a técnica do logos no

Fédon p. 115-125
Pensei então que o melhor que tinha a fazer era refugiar-me do lado das ideias

(logoi) e, através delas, inquirir da verdade (ten aletheian) dos seres (ton onton) (99e).

Temos então, no Fédon, dois registros de filósofo - o verdadeiro filósofo, equivalente ao iniciado, e o filósofo que trabalha com os logoi. O primeiro está vinculado ao conhecimento pleno, à busca pela posse da verdade sobre os seres. Essa posse plena do conhecimento só ocorre fora da vida humana - antes do nascimento - se levamos em conta o argumento da reminiscência - ou após a morte. Ou seja, o conhecimento pleno está para além da mistura corpo e alma. Porém, na segunda parte do diálogo, Platão faz uma crítica ao verdadeiro filósofo e ao conhecimento pleno, apresentando o conhecimento possível, a filosofia como busca da verdade pela alma unida ao corpo, em um trabalho com hipóteses que leva em conta o que se julga ser mais seguro a partir de um acordo entre os interlocutores.

Surge então uma dúvida: por que Platão apresenta conhecimento e filosofia desses dois modos? Por que apresentar o verdadeiro filósofo e o conhecimento pleno, para depois criticá-los? Um dos motivos seria a cena dramática do diálogo, que exige a figura do verdadeiro filósofo para superar o medo da morte. Porém, do ponto de vista gnosiológico, os dois registros de conhecimento têm papeis importantes e o movimento do diálogo mostra que um não supera o outro. A crítica à figura do verdadeiro filósofo incide sobre dois pontos: o risco da misologia e o risco da "cegueira da alma", que impossibilitam o conhecimento. Porém, criticar o verdadeiro filósofo não significa que Sócrates deixa de esperar que sua alma vá encontrar os seres puros após a morte. Ele pode manter sua esperança e pode praticar a filosofia como um iniciado, desde que essa esperança de um conhecimento pleno não o deixe paralisado enquanto em vida. Em outras palavras, não há uma krisis que exige escolha entre conhecimento pleno e conhecimento possível, entre o verdadeiro filósofo e a técnica do logos.

O plano iniciático no qual a apreensão dos seres é colocada na parte inicial do Fédon mostra um limite da filosofia, a inatingibilidade da contemplação das realidades puras pela alma em sua mistura com o corpo. Esse limite deve ser conhecido e respeitado. Isso não significa que o conhecimento filosófico, para Platão, fica comprometido para o homem em sua condição de misto corpo e alma. A posse plena do conhecimento como encontro dos seres, ou das formas, pela alma pura seria o paradigma do conhecimento perfeito, mas esse não é o conhecimento humano. Ele representa o modelo ideal de conhecimento. A alma, em sua mistura com o corpo, não atingirá plenamente esse conhecimento. Cabe a ela o conhecimento possível, a investigação filosófica com base no que parece mais seguro, mas tendo o conhecimento pleno como horizonte. Assim, a ação do filósofo terá como base a busca da beleza, da temperança, da justiça, da coragem e da própria phronesis, procurando se aproximar o máximo possível da verdade. 
ADLURI, V. (2006). Initiation into the Mysteries: The experience of the irrational in Plato. Mouseion s. III, vol. 6, p. 407-423.

AZEVEDO, M. T. S. (2000). Platão. Fédon. Introdução, tradução e notas. Brasília, Ed. UnB. BERNABÉ, A. (2011). Platão e o Orfismo. Tradução de D. Xavier. São Paulo, Annablume. BOSTOCK, D. (1986). Plato's Phaedo. Oxford, Clarendon Press.

BURGER, R. (1984). The Phaedo: a platonic labyrinth. Yale University Press, New Raven and London.

CASERTANO, G. (2014), Discurso lógico e exigência ética no Fédon. Hypnos, vol. $32, \mathrm{n}^{\circ} 1$, p. 1-19.

DIÈS, A. et alii (1993). Platon. Oeuvres Complètes. Paris, Les Belles Lettres.

MOMBELlO, E. H. (2003). Una lectura 'lógica' de Phaid. 100a3-7, Plato 3 [On line]: jan. Disponível em URL: http://gramata.univ-paris1.fr/Plato/article35.html, consultado em 28 fev. 2015.

RIEDWEG, C. (1987). Mysterienterminologie bei Platon. Berlin, Philon und Klemens von Alexandrien.

ROBINSON, R. (1953). Plato's Earlier Dialectic. Oxford, Clarendon Press.

SOUZA, J. C. (2006). Platão. Banquete. Introdução, tradução e notas. São Paulo, Difel.

SOUZA, E. C. (2015). Contemplação das formas e os limites do conhecimento no Fédon e no Banquete. Philósophos - Revista de Filosofia, [S.l.], v. 19, n. 2, p. 47-67, Jan. Disponível em: <http://revistas.ufg.br/index.php/philosophos/article/view/31970>

TRABATTONI, F. (2003). Il sapere del filosofo. In: VEGETTI, M. (ed.). Platone. La Repubblica. vol. V. Napoli, Bibliopolis, p. 151-186.

_ (2010). Platão. Tradução de R. Quinália. São Paulo, Annablume.

\section{NOTAS DE FIM}

1 Encontramos referências aos mistérios e vocabulário iniciático em vários diálogos, como Górgias, Banquete, Fédon, Mênon, Fedro, Eutidemo e na República. Mais especificamente, no Fédon eu cito, como referências aos mistérios, a descida simbólica ao Hades, com uma familiaridade ao mito de Perséfone; o regresso das almas do mundo dos mortos à terra (70c); a noção de corpo-cárcere (62b); referências à morte e à imortalidade da alma; os rituais iniciatórios, a purificação e os cultos báquicos; as citações da literatura dos mistérios.

2 Propus as noções de "conhecimento pleno" e "conhecimento possível" em um artigo recentemente publicado (Souza, 2015) que trata dos limites do conhecimento no Fédon e no Banquete. No presente trabalho, proponho um aprofundamento do mesmo tema no Fédon.

3 Utilizei a tradução de Azevedo (2000) para as citações do Fédon feitas neste artigo.

4 O contato com o inteligível, logo a seguir, é tratado através do argumento da reminiscência (72e-77c), que contém também fortes elementos órficos, representados pela premissa de que a alma existiu antes do corpo.

Submetido em Junho e aprovado para publicação em Setembro, 2015.

\section{arcHaI圈}

n. 16, jan.-apr. 2016

SOUZA, E. de, Filosofia como iniciação e a técnica do logos no Fédon p. 115-125 